\title{
Petrus Martyr y la expulsión de los judíos de España
}

\author{
EleazAR Gutwirk *
}

... la verdad, cuya madre es la historia, émula del tiempo... El Ingenioso Hidalgo don Quixote de la Mancha.

\begin{abstract}
... Menard, contemporáneo de William James, no define la historia como una indagación de la verdad, sino como su origen. La verdad histórica para él, no es lo que sucedió; es lo que juzgamos que sucedió.

J. L. Borges, "Pierre Menard, autor del Quijote", Ficciones (Emece, Buenos Aires, 1978), pág. 57.
\end{abstract}

En su Historia de los judios en la España cristiana, Baer dedica solamente unas pocas líneas a las reacciones europeas a la expulsión. Aunque Baer es, sin duda, el pionero de las investigaciones serias sobre el problema de las reacciones europeas a la expulsión, se puede sugerir de todos modos que sus pocas líneas no agotan este tipo de pregunta. La contribución de Baer yace principalmente en tres puntos: la enumeración de algunas de las fuentes (aunque la mayoría ya habían sido mencionadas en la historiografía), el juicio histórico de que los humanistas del siglo XV no criticaron la expulsión y la presunción de que las reacciones se explican suficientemente, describiéndolas como «antisemitas".

La gran cantidad de documentación, que se ha hecho pública en las últimas décadas, además de la que ya se conocía en la época de Baer, significa que, en cierto modo, las fuentes narrativas como son las crónicas, las cartas, las menciones literarias incidentales, pueden llegar a parecer superfluas como fuentes de datos acerca del proceso de las expulsiones. $Y$, sin embargo, aun sin entrar en los postulados más básicos de la ciencia política ni las teorías del conocimiento, es evidente que las percepciones de un evento pueden asumir una importancia equiparable a la del hecho

* Tel Aviv University. 
en sí y que el análisis histórico que no las toma en cuenta es deficiente y parcial. Fueron las percepciones de la expulsión, y no el estudio detallado y documental, las que influyeron sobre la política de la época. En efecto, se podría argumentar que aun pasados los siglos XV y XVI la expulsión se convirtió en potente emblema de una tendencia política e ideológica de cierto peso en la imagen de España en el resto de Europa. El propósito de estas líneas es comenzar la labor de reconstruir esas percepciones. A estos efectos se puede prestar atención a uno de los escritores contemporáneos de la expulsión que nos dejó constancia de su modo de ver a los judíos en general y el acontecimiento en particular. Pedro Mártir d'Anghiera fue mencionado brevemente por Baer como uno de los humanistas que celebraron la expuisión. El valor de sus Epístolas como fuentes de datos para la historia de la expulsión se pone en tela de juicio y sus reacciones se explican como antisemitas. De hecho, ya Alexander von Humboldt, quien admiraba a Mártir, había censurado su «intolerancia religiosa»'.

En la historia de la cultura europea, Pedro Mártir es objeto de mayor atención de lo que puede imaginar el lector de las escuetas líneas que le dedica Baer. No se trata simplemente del hombre que introdujo palabras como "patata" o "canoa" en el castellano, el inglés y otras lenguas europeas. Menéndez y Pelayo lo definió como uno de los ejemplos más antiguos y notables del periodismo noticiero ${ }^{2}$. Fueter escribió que era más periodista que historiador ${ }^{3}$. Ernesto Lunardi lo denomina «ll primo americanista", y no sólo porque se le atribuye la invención del término "nuevo mundo" ${ }^{4}$.

Nacido el 2 de febrero de 1457 en Arona sobre el Lago Maggiore, en aquel entonces posesión de la familia Borromeo, condes de Arona, llegaría a exaltar en tiempos posteriores la nobleza de su familia. Fue discípulo del humanista Filelfo. En 1477 deja Lombardía para llegar a Roma. Enseñó en Rieti en 1482. Fue secretario de Francesco Negro en Perugia, cuando éste era Gobernador. Cuando Íñigo López de Mendoza, conde de Tendilla, llega a Roma para ofrecer su homenaje al nuevo Papa, Inocenzo VIII,

BAER, A. History of the Jews in Christian Spain. Filadelfia 1966, pág. 513, nota 15 al cap. XV: "Also among the antisemites who justified the expulsion was Petrus Martyr." Véase también SCHNEIDER, H., «Humboldt als kritiker spanischer und portugiesicher Literatur», Zeitschrift der Gesellschaft fur Erdkunde Alexander von Humboldt, 1959.

2 "Estudios y discursos de crítica histórica y literaria», Edición Nacional de las Obras Completas, C.S.I.C., t. VIl. Madrid 1941, págs. 81-82.

3 Storia della storiografia moderna. Milán-Nápoles 1970, pág. 299.

4 LUNARDI, Ernesto, "Pietro Martire d'Anghiera. Il primo americanista nella storia e nella cultura del suo tempo", en Terra Ameriga, n. ${ }^{\text {os }} 37-40,1976$. 
Pedro Mártir escribe un poema en su honor. Es entonces cuando se le invita a venir a España con el conde. Allí pudo haber conocido al judío Samuel Frances, quien estaba al servicio del conde y a quien un documento de 1480 describe como cjudío mayordomo de Íñigo López de Mendoza" ${ }^{5}$. Sus contactos con los Mendozas, con Hernando de Talavera y otros latinistas le sirvieron en su carrera, como también le sirvió la tendencia a promover la educación humanística en la corte de los Reyes Católicos. Después de varias cartas de lisonja logra su propósito de ser maestro humanista en la corte de los Reyes Católicos. Después de la conquista de Granada se le otorga un salario como canónigo de la catedral de Granada. En 1502 (26 de enero) viaja como enviado al Sultán de Egipto para discutir temas tales como el tratamiento de los cristianos en el medio oriente, las restricciones que sufren los peregrinos cristianos a Tierra Santa y para explicarle al sultán el mal trato de los cristianos a los moros de Granada.

Las reacciones de Petrus Martyr a la expulsión están inscritas en su Opus Epistolarum. La primera edición es posterior en varios años a la muerte del autor, ya que fue publicado en Alcalá de Henares en 1530 y reimpreso en Amsterdam en $1670^{6}$.

Las reacciones a la expulsión no deben leerse aisladamente, sino dentro del contexto de las referencias a los judios en su obra en general. Ya en 1487 explicaba su estancia en España, diciendo que era el único país feliz que tiene la suerte (cosa que hasta entonces le había sido negada) de tener príncipes amantes de la religión (pags. 5-6). La primera de estas referencias parece ser su carta 14 (págs. 19-20). En esta carta de 6 de mayo de 1488 se dirige a Isabel la Católica. Dice que cuando él andaba en Roma uen boca de todos los italianos corría la voz de que en nuestro tiempo había bajado del cielo una mujer admirable... la cual... juntamente con su esposo había afianzado en toda España la religión cristiana, espantada ante la perfidia de los judíos". La compara a "Semiramis o a alguna hija de Lesbos", menciona su deseo de abrir una academia para los jóvenes de la corte.

Ya en esta carta, relativamente temprana, se pueden discernir algunas características de las actitudes hacia los judios de su obra. Ante todo, el marco general de su actitud hacia los judíos. Los judíos no fueron la más constante preocupación de Mártir como lo habían sido de, por ejemplo,

\footnotetext{
5 BAER, F., Die Juden im Christlichen Spanien, vol. II. Berlín 1936, pág. 348.

6 Epistolario, ed. José López de Toro. Madrid 1953, las referencias en el texto son a esta edición.
} 
Alonso de Espina. Este marco general es el de su posición con respecto a los Reyes. Alberto Bemporad lo describe como "ambizioso anche un po, avventuriero come tutti gli umanisti di allora e non solo di alloram. Algo de esto se vislumbra ya en esta carta. Al tratar de conseguir el tipo de posición a la que han accedido sus colegas humanistas sigue sus huellas. El tono adulatorio de las epístolas se refuerza con la alusión clásica. Este tipo de imágenes, como asimismo la tantas veces discutida hipérbole divina, pueden relacionarse con el profundo deseo o necesidad de legitimidad de la dinastía Trastamara, en general, y de la preocupación por manejar la opinión pública, que se ha notado varias veces en los estudios sobre la mentalidad de los Reyes Católicos. Este tipo de articulación de la ideología oficial de los monarcas no es una mera suposición hipotética, sino un hecho que ha sido confirmado en varios estudios sobre temas particulares y concretos. En el plano institucional, por ejemplo, se han examinado las descripciones de la Santa Hermandad en las crónicas oficiales con los antecedentes y con los documentos. Lo mismo se ha hecho con la institución del corregidor. El estudio de la imagen de Abraham Seneor en fuentes historiográficas de los siglos XV y XVI lleva a la conclusión de que no se puede entender el tratamiento de Seneor como parte de la tradición historiográfica de descripciones de judíos, sino dentro de la corriente de historiografía propagandística a favor de los Reyes Católicos, especialmente de Isabel. También se ha examinado la historiografía en prosa y en verso, la poesía encomiástica y las posturas mesiánicas.

Así, por ejemplo, Milhou resaltaba la utilización de profecías mesiánicas (como ser el caso de la Historia del Marqués de Cádiz) para fines financieros:

Si l'utilisation de ces propheties servait la politique des Rois Catholiques vis-a-vis de la noblesse, elle servait aussi leur politique de transformation de la bulle de croisade en un veritable impot national: si l'Espagne continuait sa lutte contre L'Islam au-dela de la reconquete de Grenade jusqu'a Jerusalem, il n'y avait pas de raison de payer des decimes a la papaute pour financier le budget de Rome, a travers de celui de la croisade pontificale.

Dentro de esta tendencia general, P. Cátedra ha llegado a identificar una más particular. Según él, "al final de la campaña de 1485 se percibe la primera andanada propagandística seguramente organizada desde el poder... El esfuerzo... propagandístico... no se agotó (después de 1485)..., sino que resonaba cada vez con más fuerza». La situación internacional lleva a «que se acentuara la propaganda». La Consolatoria de Castilla, de Juan Barba, es sólo un ejemplo de toda una literatura propagandística que es paralela a la campaña militar. Todos estos minuciosos estudios 
de Lunenfeld, Milhou, Cátedra, y otros, revelan hasta qué punto y en cuántos variados géneros se cuidaba la propagación de una ideología providencialista, centralizadora y que enfatizaba el papel de los Reyes ${ }^{7}$.

La epístola de Mártir puede entenderse como un ejemplo de la explotación de ese afán de propaganda para promover fines personales. Ésa sería la función de las referencias clásicas en la epístola y la mención de la fama de Isabel en Roma. Lo característico de Mártir es el relacionar esta estrategia discursiva a la política judía de la Reina. Su perspicacia en entender que esta política era más importante en España y en la corte, que en otras partes de Europa, no es única. Los viajeros que visitan España en el siglo xv prestan particular atención a la presencia judía o conversa: es éste el caso de Leo Rozmithal, Marineo Sículo y aún de Guicciardini ${ }^{8}$. Finalmente, la referencia en esta epístola número 14 a que los Reyes "habían afianzado en España la religión cristiana espantada ante la perfidia de los judios», debe ser una referencia a las actividades de la Inquisición. La perfidia iudaeorum es, como bien se sabe, una frase tomada de la liturgia cristiana de Pascua, pero conviene notar esta alusión a imágenes de deslealtad y mentira en una epístola de $1488^{\circ}$.

La epístola sobre la expulsión, número 92, lleva fecha del 11 de marzo de 1492. Va dirigida al cardenal Giovanni Archimbaldi, arzobispo de Milán. La mayor parte de la epístola está dedicada a describir en tonos triunfalistas la conquista de Granada. Pero, escribe Mártir:

Acometen los Reyes otra gran empresa: Al darse cuenta que con el contagioso trato con los judios - un número incontable, de los cuales es

\footnotetext{
7 Bemporad, Alberto, in "Seduta di apertura", Pietro Martire d'Anghiera nella storia e nella cultura. Génova 1980, pág. XXVI. GUTwIRTH , E., «The Reputation of Abraham Seneor in the 15th and 16th Centuries", en idem, Social tensions within 15th Century Hispano-Jewish Communities, Ph. D. Thesis, University of London, 1978, ch. V. Appendix II. LunENFELD, M., The Council of the Sta. Hermandad. Coral Gables 1970. MiL.hOu, A., "Le Chauve-souris, le nouveau David et le roi Cache trois images de l'empereur des derniers temps dans le monde iberique: xII-xvième siècles", Melanges de la Casa de Velázquez, $n^{\circ} 18,1982$, págs. 61-78, 71 e idem, Colon y su mentalidad mesiánica en el ambiente franciscanista español. Valladolid 1983. CátEDRA , P. M., La historiografia en verso en la época de los Reyes Católicos. Salamanca 1989, págs. 79-80.

- Gazzerro Righi, Luisa, "L'Opus epistolarum di Petrus Martyr visto alla luce della critica tedesca della fine del XIX secolo", Pietro Martire d'Anghiera nella storia e nella cultura. Génova 1980, págs. 261-285.

3 Motis Dolader, M. A., "Estudio de los objetos litúrgicos de las sinagogas zaragozanas embargadas por la corona en el año 1492», Aragón en la Edad Media: Estudios de Economia y Sociedad, VI, 1984, págs. 247-262; idem, «Documentos para el estudio de la expulsićn de los judíos de Magallon", Tvriaso, n V, 1984, págs. 211-251; idem, La expulsión de los judios de Zaragoza. Zaragoza 1985; idem, Los judíos de Magallon (Zaragoza) a fines del siglo xv y su expulsión", Cuadernos de Estudios Borjanos, n. ${ }^{\text {s }}$ XVII-XVIII, 1986, págs. 141-248; idem, La expulsión de los judios del reino de Aragón. Zaragoza 1990. BAER, Die Juden, nII, págs. $404 \mathrm{ff}$.
} 
actualmente en España mucho más rico que los cristianos - muchos de estos últimos se corrompian y eran seducidos, se les señaló un día determinado para que a los cuatro meses de la publicación del edicto se marcharan de España. Todo el que no lo hubiera hecho así para esa fecha, sería preso o muerto, a voluntad del que lo descubriese. Así lo anuncian los pregoneros por todos los reinos sujetos a la jurisdicción real. Por fin es lanzada al destierro esta raza, sagaz en grado superlativo para sacar el dinero dondequiera que sepan está escondido: engañosa adoradora del oro con el corazón y del Dios de la Antigua Ley con la boca... Desde la ciudad de Granada, a 11 de marzo de 1492.

La segunda carta es del 20 de marzo de 1492. Fue enviada a Giovanni Borromeo, conde de Arona, es decir al noble de su ciudad natal. La mayor parte de la epístola está dedicada a una comparación entre Roma y Milán y al estado de los correos. Pero hay un párrafo acerca de las novedades del momento:

Recibe, pues, por conducto de nuestro compatriota Francisco Adam, que se dirige ahí, este breve resumen de los acontecimientos bélicos de nuestro tiempo: En diez años César sometió a las Galias; en diez años de campañas anuales mis Reyes debilitaron, vencieron y destruyeron de raíz - habiendo caído en poder suyo dos de sus Reyes- a este pueblo venido de Mauritania, que infestó España durante cerca de ochocientos años. Aunque eran innumerables y más ricos que los cristianos, expulsaron a los judios - raza falaz- por contagiar los espíritus cristianos con sus supersticiones. Desde la ciudad de Granada, a 20 de marzo de 1492.

En los dos textos hay cierta discrepancia entre el tono triunfal y la analogía a los hechos grecorromanos por un lado y a la expulsión de los judíos por otro. Es difícil equiparar la destrucción de Troya y la conquista de Galia con la expulsión de una minoría. Pedro Mártir lo logra por medio de la creación de una imagen de los judíos como enemigos poderosos «innumerables y más ricos que los cristianos». En las dos cartas aparece la imagen de los judíos como enfermedad: los judíos contagian, corrompen.

Para Baer, el interés de las cartas radicaba en la fecha de las mismas. En su Historia de los judíos en la España cristiana, Baer escribe que en la epístola 92 aparece una carta escrita en Granada el 11 de marzo de 1492, en la cual se proclama la expulsión con gran satisfacción. Según Baer, los copistas interpretaron mal la fecha y confundieron el orden cronológico. Mantiene esto porque el edicto fue hecho público sólo a fines de abril o principios de mayo. Baer no alega fuentes para este tipo de indagación, pero, de hecho, investigaciones sobre las fechas del Opus Epistolarum son típicas de la erudición germana del siglo xIX. En efecto, las fechas de las cartas son el objeto de trabajos tales como el de 
J. Gerigk, Das Opus Epistolarum des Petrus Martyr, ein Beitrag zur Kritik der Quellen des ausgehenden 15. und beginnenden 16. Jahrhunderts (Koenigsberg Dissertation), Braunsberg 1881, como también el de H. Heidenheimer, Petrus Martyr Anglerius und sein Opus epistolarum. Ein Beitrag zur Quellenkunde des Zeitalters der Renaissance und Reformation, Berlín 1881. El Petrus Martyr Anglerius und sein Opus Epistolarum, Strassburg 1891, de J. Bernays, es especialmente instructivo. En efecto, Gerigk había afirmado que Pedro Mártir debía haber poseido dones proféticos, puesto que se refiere en varias cartas a hechos posteriores a la fecha que encabeza la epístola. De las 812 cartas del Opus encuentra Gerigk alrededor de 40, en las cuales se nota este tipo de contradicción. La hipótesis de Bernays es que hubo una edición de fragmentos de cartas unidos por fórmulas, a las cuales denomina bindeglieder. Hoy en día parece ser que se han aceptado en parte las conclusiones de la erudición germánica decimonónica, aunque se tiende, por lo general, a calificarlas de hipercríticas. Como ya se ha dicho, el problema desaparece, en cierto modo, si cambiamos de perspectiva y nos interesamos más por sus percepciones de la expulsión que por los datos. En los párrafos que he mencionado me parece ver dos obsesiones tópicas en particular. La primera es la del judio mentiroso, falaz y la segunda es la de los judíos como enfermedad contagiosa. La identificación de estos dos tópicos puede ser de interés dentro del marco de los breves y casuales juicios que se han emitido sobre el tema de Mártir y los judíos de su época. En efecto, Franceso Giunta ${ }^{10}$ hablaba de Mártir como "conformista" (pág. 303): «L'altro aspetto del conformismo di Petrus Martyr riguarda la politica religiosa dei sovrani spagnoli... la persecuzione degli eretici attraverso lo strumento di quell'inquizisione che egli definisce "sacrosanta"." Dentro de este "conformismo religioso" la posición antisemita de Mártir es suficientemente notable como para que se describa como "consistente" (pág. 303): "Piu sostenuta e la posizione antisemita di Pietro Martire... appoggia senza riserve la politica dei re cattolici contro gli Ebrei descritti sempre con toni negativin. Sin embargo, mientras que respecto a la "política religiosa" se le describe como "conformista" con las connotaciones de pasividad que lleva el concepto en otros casos similares, se le considera como agente más activo. Así, por ejemplo, con respecto a la política diplomática, Francesco Giunta lo declara (pág. 297): "strumento attivo della diplomazia spagnola... non siamo dinanzi ad uno spettatore passivo". Mártir debe seleccionar, elegir entre varios topoi del antisemitismo medieval. Esta acción de seleccionar

10 Giunta, Francesco, "Pietro Martire d'Anghiera e le guerre d'ltalia», Pietro Martire d'Anghiera nella storia e nella cultura. Génova 1980. 
no se ha tenido suficientemente en cuenta a la hora de determinar su posición. Más aleccionadora aún es la consistencia y la repetición de estos topoi en su obra. Estos datos pueden llevar a un análisis diferente al de Giunta. Y es aquí donde adquieren más relevancia los escritos marginales de Mártir. Los poemas ocasionales, que se le conocen, sugieren algo más que un pasivo conformismo. Aparte de la edición de Sevilla de sus obras, hay una edición impresa por J. Vignaude de los poemas solos, de Valencia 1520, que lleva el título Poemata in quibus supreme laudes Catholicorum Regum continentur. Uno de ellos es el Pluto furens, Plutón encolerizado. Petrus Martyr lo escribe para Diego López de Haro y se lo dedica a Alejandro VI. En este poema Plutón, dios de las fuerzas infernales, está encolerizado por el casamiento de Fernando e Isabel y la unión de sus coronas. Plutón, enemigo del género humano, es a la vez protector del infiel, es decir, de judios y moros. Su poema "lanus" fue escrito después del pacto de Salamanca (24 de noviembre de 1505), alrededor del 1 de enero de 1506. En él escribe que los moros y judíos creen que ha llegado el momento de la venganza. Quieren reivindicar la caida de Granada y los muchos que han sido quemados en vida ${ }^{11}$ (pág. 293).

Pero la expresión más desarrollada de sus opiniones acerca de los judíos es la que se halla en el reporte que escribió para describir su misión diplomática al Cairo de 1502, es decir, la Legatio Babylonica ${ }^{12}$. En esta apología, por su misión diplomática al Cairo, Mártir se refiere varias veces a los judios y a su expulsión de España. La idea básica de todo el libro es que Pedro Mártir logra convencer al sultán de la justicia de la política de los Reyes Católicos, a pesar de las intrigas de los musulmanes norteafricanos y de poderosos judíos en la corte del sultán. En este escrito, Mártir refiere que al llegar no se le quiso recibir. Cuando se le dice que el sultán teme la sublevación de sus súbditos si lo recibe, Mártir se niega a creer en esta explicación. La verdad, dice, es que los judíos desterrados de España y los moros hablaron mal de él. Le habían dicho al sultán que el embajador, Mártir, habia llegado con poca escolta y sin regalos. Mártir explica al lector que éstos son los más orgullosos de los bárbaros que creen que llegar sin escolta y regalos es signo de desprecio. Mártir cuenta que envió dos franciscanos con un mensaje al sultán, diciendo que se le había informado que calumniadores habían influido sobre el sultán con

"CORTe, Francesco della, "I Carmina di Petrus Martyr", Pietro Martire d'Angiera nella storia e nella cultura. Génova 1980, págs. 187-194.

${ }^{12}$ Una embajada de los Reyes Católicos a Egipto, ed. Luis García y García. Valladolid, C.S.I.C., 1947, las referencias en el texto son a esta edición. 
sus falsas acusaciones. Y aquí (pág. 82) es donde aparece un pasaje que se refiere a la expulsión:

Mas que estas gentes pérfidas, enemigas de la paz y la concordia de los Reyes, semillero de sedición y discordias, expulsadas por los Reyes Católicos como una peste perniciosa, hayan dicho que el embajador no ha venido ante vos, que sois tan grande príncipe, decorosamente acompañado, es una acusación tan falsa como envidiosa (pág. 80).

Luego, cuando está por ser recibido por el sultán, descubre, según él, que los norafricanos que habian sido pagados por los desterrados judios y moros habían planeado una rebelión con el pueblo y la nobleza. La gente del sultán se lo había comunicado y por eso éste se mostraba reacio a recibir a Mártir. Proclamaban que un sultán que recibe bien al embajador de unos monarcas que son enemigos de su religión, se alegraría con la ruina de los moros (pág. 142). Cuando los embajadores del norte de África tratan de descreditar al traductor de Pedro Mártir, éste manda otra misiva más. En ella dice que aunque no está obligado a dar explicaciones, va a explicar muy claramente sus argumentos en contra de los de los judíos exiliados de España, quienes habian sido movidos por su vileza (pág. 148).

Finalmente, un domingo antes del amanecer se le permite entrar por una puerta secreta. Los primeros tópicos de la discusión entonces fueron la derrota de Granada y la expulsión de los judios de España. Mártir argumenta ante el sultán que las conversiones forzadas están en contra de la doctrina cristiana. La enorme masa de judios desterrados no había sido forzada a convertirse. De los judíos y conversos sin religión no se debe preocupar el sultán ni debe parecerle asunto de importancia (pág. 150). Y es aquí que Mártir elabora su diatriba más largamente:

Pág. 162. De los judios y demás neófitos sin ley ipara qué os vais a preocupar? ¿Qué os importan? Éstos fueron eliminados por mis Reyes de todos sus reinos como una peste deleterea. iOh!, si supiéseis que morboso, pestífero y contagioso es ese ganado de que habláis. Todo lo corrompen con sólo tocarlo, lo infectan con la mirada, lo destruyen con la lengua, trastornan 10 divino y lo humano, lo inficionan, 10 deshacen, asedian a sus desgraciados vecinos, les roban de raíz, los deshonran; dondequiera suponen que hay dinero, como perros ventores van detrás... Algún sabréis... qué clase de hombres son éstos a quienes protegéis y mezcláis con vuestras ovejas; conoceréis lo obscenos, detestables, viles y execrables que son; os daréis cuenta que deben ser apartados de todo comercio humano y entonces habréis de confesar que mis Reyes fueron los más sabios de los hombres, precisamente porque pensaron en exterminar a ganado tan despreciable y morboso.. ¿Qué queréis que os cuente de esta raza abyecta? Acaso un ladrón o un pérfido traidor a quien 
creyéndole vos reo de muerte únicamente le desterrárais o mandárais azotar, cuando fuera a tierras extrañas, alabaría a vuestra majestad? ¿Os llamaría clemente y misericordioso? No, por cierto...

Más adelante en la Legatio Babilonica, Pedro Mártir incluye algunas descripciones de curiosidades locales de Egipto. El espíritu exoticista que se le atribuye en el sentido de alabar lo extraño por el hecho mismo de su exotismo, no se manifiesta aquí del mismo modo que en sus descripciones del nuevo mundo. Entre varias otras (por ejemplo, las pirámides), relata una leyenda (pág. 188) acerca de una plantación de bálsamo alrededor de una fuente donde se aseguraba que había lavado María los pañales del Niño Jesús durante la época en que estuvo oculto en Egipto. La plantación se había secado. Para explicar esto se ofrecen dos cuentos. Uno atribuye la decadencia de la plantación a la ropa interior de una mujer «manchada con el flujo menstrual» y que era tan terrible la fuerza y el vigor del veneno menstrual que, infectada por el agua, los riachuelos que pasaban junto a los árboles quemaban las raíces de éstos".

El otro cuento atribuye el estado de la plantación a un judío convertido:

"Los antiguos sultanes ordenaron que ninguna persona de ningún sexo entrase en la plantación del bálsamo, no fuera a perpetrarse alguna ignominia contra lo sagrado de aquel recinto, pues en aquella fuente lavaba siempre la Virgen María los pañales en que envolvía al Niño Jesús durante la época en que estuvo oculto en Egipto... Dicen que para la guarda del jardín pusieron imprudentes administradores del sultán a un judío que se decía moro y él llevó allá consigo a su mujer; ambos introdujeron a un hijo suyo pequeño en la misma fuente en que se había lavado Cristo; para mayor escarnio metieron también en el agua los pañales y los tendieron a secar. $Y$ cuentan que por esto la tierra, por cuya virtud germinaban los arbustos y la fuente con cuyas aguas eran regadas..., inmediatamente después de esta afrenta perdieron por completo su eficacia" (pág. 188).

Los componentes de la polución y la mentira (cf. un judío que se decía moro) están presentes en este relato. De sumo interés es la confluencia de componentes misóginos y antisemitas en estos párrafos de la Legatio.

El relato de la embajada a Egipto de Mártir, como otros de este tipo, deben leerse, por supuesto, como esfuerzos por realzar la contribución personal del embajador. De allí, la extensión de los párrafos dedicados a describir las dificultades en obtener acceso al sultán. Pero en el marco particular de esta investigación la principal pregunta es cuál es la significancia del uso consistente y dilatado de estos topoi sobre los judíos.

En parte existe una necesidad funcional de desacreditar acusaciones de crueldad en contra de judios y moros. También se puede concebir que 
los vagos rumores descritos por Mártir hayan tenido cierta base. En efecto, ésta es la época de las actividades de judíos, como Jacob Așugair. Si fuese esto así, los historiadores de la comunidad judía de Egipto, a principios del siglo $\mathrm{XVI}$, tendrían que prestar más atención al relato de la Legatio de lo que éste ha merecido hasta hoy. Pero una explicación funcional de este tipo no puede ser suficiente. Aun si el estudio histórico de las percepciones en este sentido puede decirse que está en su infancia, creo que se ha demostrado suficientemente que no se trata de una referencia ocasional debida a la situación en El Cairo y que se ha indicado la particular intensidad de dos topoi en las referencias a los judíos en otros pasajes de la obra de Mártir. Hasta que no se aleguen pruebas contrarias, se debe destacar el acto de elección de entre los varios topoi antisemitas que podría haber utilizado Mártir. Sobre todo debe hacerse hincapié sobre lo que asume la carta acerca de las reacciones que provocaría en su público, es decir, la corte de los Reyes Católicos. Lo más notable en este contexto es que la retórica de lepra, polución y contaminación está presente en el universo discursivo del edicto de expulsión del 31 de marzo de 1492. En la versión de Aragón, Cataluña y Valencia del Archivo de la Corona de Aragón notamos verbos como uremediar", "extirpar». Hay justificaciones de la decisión por medio de frases como ser "la salud de las animas de los christianos" o "los que por contagio pueden danyar a otros" $y$, finalmente, la significativa frase: «echasemos dellos (de los reinos) perpetuamente e para siempre los dichos judios e judias diziendo que tal leptra y tan contagiosa si no con la dicha expulsion no era posible remediar".

El estudio de tales componentes del discurso político de la época no puede contentarse con describirlos como «antisemitas" sin más, dando a entender que existe una cierta homogeneidad en todas las percepciones cristianas de la expulsión. Al contrario, debe prestarse atención a las particulares resonancias de estos topoi para un público de la época. El tema del judío «mentiroso=falso=desleal" ha sido estudiado en otro lugar a base de textos hispanos cristianos (especialmente en romance castellano) en base al Pugio Fidei, a los Milagros de Berceo, el Cavallero Cifar, la Crónica de Juan II, etc., y se ha relacionado con otro tópico: el del judío "Sagaz" $=$ «Sotil» ${ }^{13}$.

Pero estos topoi tienen algo más que resonancia filológica. Puede afirmarse que varían de acuerdo al contexto político e histórico, en el cual

13 GutwiRTH, Eleazar, "The Jews in 15th Century Castilian chronicles", Jewish Quarterly Review, LXXXIV, n4, abril de 1984 (1986), págs. 379-396. 
se articulan. Después del establecimiento de la Inquisición, tendrian un significado diferente. Al nivel más básico es precisamente la «falsedad» de la conversión lo que justifica el establecimiento de la institución.

En el estudio del tópico del ajudio como leproso o como enfermedad contagiosa" también puede indagarse el contexto en el cual se articula. Así, por ejemplo, no veo especial mérito en ignorar las circunstancias personales de Mártir y sus experiencias de la plaga tanto en la Italia de su juventud como en la Castilla de fines del siglo XV (por ejemplo, en Sevilla en los años ochenta). No se trata de someter a un análisis a Mártir, sino a su texto y su lenguaje. Debe tener en cuenta también la posibilidad de ecos lejanos de lo que R. I. Moore denomina «the development during the twelfth century of a rhetoric of contamination against dissidents and minority groups-especially heretics and Jews»" 14 .

La conexión metafórica entre judios y lepra tiene un fondo histórico que conviene recordar: Textos del siglo III AC refieren la leyenda de los judíos desterrados de Egipto como leprosos y contaminados ${ }^{15}$. En 1321 , la idea de que los judios y los leprosos se habian asociado en un complot para derribar a la cristiandad ganaba la aceptación de una gran parte de la sociedad francesa ${ }^{16}$. El estudio de $\mathrm{H}$. Goldberg acerca de los paralelos entre los tópicos antisemitas y misóginos es especialmente importante, porque subraya las afinidades entre las ideas de la impuridad de las mujeres y la de los judíos en los textos hispano-medievales que constituyen el marco ideológico de la recepción de las opiniones de Mártir en España ${ }^{17}$.

En conclusión: la explicación de «antisemitismo" o "conformismo» que se han sugerido de manera casual para las actitudes de Mártir hacia los judíos, en general, y hacia la expulsión de los judíos, en particular, son insuficientes por varios motivos.

Tienden a agrupar autores diferentes que reaccionan ante la expulsión de una manera que pueden describirse como antisemitas. Pero tal des-

14 "Guibert of Nogent and his World", Studies in Medieval History... R. H. C. Davis, ed. H. Mayr-Harting and R. I. Moore. Londres 1985, 107-118, pág. 111.

is La asociación metafórica entre los judíos y la lepra puede remontarse al Aegyptiaca de Lysimachus [según se cita en Contra Apionem] a Tacitus y nociones similares pueden ser halladas en Diodorus, Chaeremon. Véase STERN, M., Greek and Latin Authors on Jews and Judaism, vol. I. Jerusalén 1976, pág. 383 ff; vol. 2, Jerusalén 1980, pág. 35 ff.

i6 Barber, M. "Lepers, Jews and Moslems: The plot to overthrow Christianity in 1321", History, $\mathrm{n}^{\circ} 66,1981$, págs. 1-17.

17 Goldberg, Harriet, “Two Parallel Medieval Commonplaces: Antifeminism and Antisemitism in the Hispanic Literary Tradition", en Aspects of Jewish Culture in the Middle Ages. Albany, Nueva York, ed. P. E. Szarmach, 1979, págs. 85-119. 
cripción oculta los matices de diferentes reacciones. Aunque tanto a Bernáldez como a Mártir se les puede describir como antisemitas, el primero demuestra un grado de identificación con las víctimas de la expulsión que se buscará en vano en los párrafos de Mártir. La repetición de los topoi del «judío mentiroso" y el «judío leproson se nota a través de textos que van desde los años ochenta hasta entrado el siglo xvI. Sin tratar de comprender los contextos personal, histórico y aún filológico de estos topoi, no se puede entender su significado dentro de los textos. La construcción de una imagen de antisemitismo "homogéneo" no se puede mantener teóricamente. Más bien es necesario realzar los matices y las contradicciones en las reacciones europeas a las expulsiones. 